\title{
I 083 Reproducibility of right atrial volume and ejection fraction in healthy subjects and patients with right heart failure using the standard short axis and area-length method Burkhard Sievers*1, Marvin Addo ${ }^{2}$, Frank Breuckmann1, Joerg Barkhausen ${ }^{3}$ and Raimund Erbel ${ }^{1}$
}

\begin{abstract}
Address: ${ }^{1}$ West German Heart Center, Cardiology, University Hospital Essen,, Essen, Germany, ${ }^{2}$ Department of Cardiology, University Hospital Cologne, Cologne, Germany and ${ }^{3}$ Department of diagnostic and interventional Radiology and Neuroradiology, University Duisburg-Essen, Essen, Germany

* Corresponding author
\end{abstract}

from I Ith Annual SCMR Scientific Sessions

Los Angeles, CA, USA. I-3 February 2008

Published: 22 October 2008

Journal of Cardiovascular Magnetic Resonance 2008, I0(Suppl I):A208 doi:10.II86/1532-429X-I0-SI-A208

This abstract is available from: http://jcmr-online.com/content/I0/SI/A208

(C) 2008 Sievers et al; licensee BioMed Central Ltd.

\section{Background}

Measurements of atrial volumes and ejection fraction (EF) are superior to diameters for both accurate determination of the atrial size and follow up studies. Changes of right atrial volume and EF might have a prognostic impact in patients with right heart failure. We therefore sought to evaluate the reproducibility of right atrial volumes and EF in healthy subjects and patients using the standard short axis method (SA) and the rapid area-length method (ALM).

\section{Methods}

Right atrial volumes (maximum and minimum) and EF were measured in 10 healthy subjects and 10 patients with right heart failure using SA and ALM. Images were acquired with a steady state free precession gradient-echo sequence on a clinical 1.5 Tesla magnetic resonance scanner (Siemens, Erlangen, Germany). For SA, volumes were determined by the sum the outlined areas. EF was calculated as follows: $\mathrm{EF}=(\mathrm{EDV}-\mathrm{ESV}) / \mathrm{EDV} \times 100$. For AML, the right atrial area and length were measured from the horizontal long axis view. Minimum and maximum volumes were calculated as follows: $8 \times(\text { Area })^{2} / 3 \pi \times$ Length, EF $(\%)=($ Maximum volume - Minimum volume $) /$ Maximum volume $\times 100$. All patients were examined twice (scan 1 and 2). Both scans were performed at the same day.

\section{Results}

For SA, maximum volumes, minimum volumes and $\mathrm{EF}$ for healthy subjects were $95.4 \pm 19.9 \mathrm{~mL}, 47.9 \pm 8.9 \mathrm{~mL}$, $49.0 \pm 8.1 \%$ in scan 1 and $95.8 \pm 17.5 \mathrm{~mL}, 49.5 \pm 11.2 \mathrm{~mL}$, $48.1 \pm 8.8 \%$ in scan $2(\mathrm{p}=0.285)$. SA-volumes and $\mathrm{EF}$ for patients in scan 1 and 2 were $145.2 \pm 28.2 \mathrm{~mL}, 106.9 \pm$ $25.9 \mathrm{~mL}, 26.5 \pm 9.7 \%$ and $146.3 \pm 26.3 \mathrm{~mL}, 109.9 \pm 23.9$ $\mathrm{mL}, 24.9 \pm 9.8 \%$, respectively $(\mathrm{p}=0.139)$. SA-interstudy variability was $-0.3 \pm 7.9 \mathrm{~mL},-1.6 \pm 4.9 \mathrm{~mL}$ and $0.9 \pm 3.5 \%$ for healthy subjects (Figure 1A) and $-1.1 \pm 6.8 \mathrm{~mL},-3.0 \pm$ $5.2 \mathrm{~mL}$ and $1.7 \pm 2.7 \%$ for patients, respectively (Figure 1B).

For ALM, maximum volumes, minimum volumes and EF for healthy subjects were $89.3 \pm 19.4 \mathrm{~mL}, 43.7 \pm 8.0 \mathrm{~mL}$, $50.1 \pm 8.3 \%$ for scan 1 and $81.7 \pm 15.8 \mathrm{~mL}, 38.7 \pm 7.5 \mathrm{~mL}$, $51.8 \pm 10.3 \%$ for scan $2(\mathrm{p}=0.114)$. ALM-volumes and EF for patients in scan 1 and 2 were $139.9 \pm 28.3 \mathrm{~mL}, 103.7$ $\pm 26.9 \mathrm{~mL}, 26.5 \pm 10.3 \%$ and $141.2 \pm 28.2 \mathrm{~mL}, 104.9 \pm$ $28.0 \mathrm{~mL}, 26.1 \pm 10.1 \%$, respectively $(\mathrm{p}=0.575)$. ALMinterstudy variability for healthy subjects was $7.6 \pm 12.3$ $\mathrm{mL}, 5.0 \pm 8.1 \mathrm{~mL}$ and $-1.7 \pm 3.1 \%$ (Figure $1 \mathrm{C}$ ) and for patients $-1.3 \pm 22.7 \mathrm{~mL},-1.7 \pm 20.7 \mathrm{~mL}$ and $0.4 \pm 3.9 \%$, respectively (Figure 1D). Volume and EF differences for healthy subjects between scan 1 and 2 were smaller for SA compared to ALM (Table 1). 


\section{Shortaxis method}

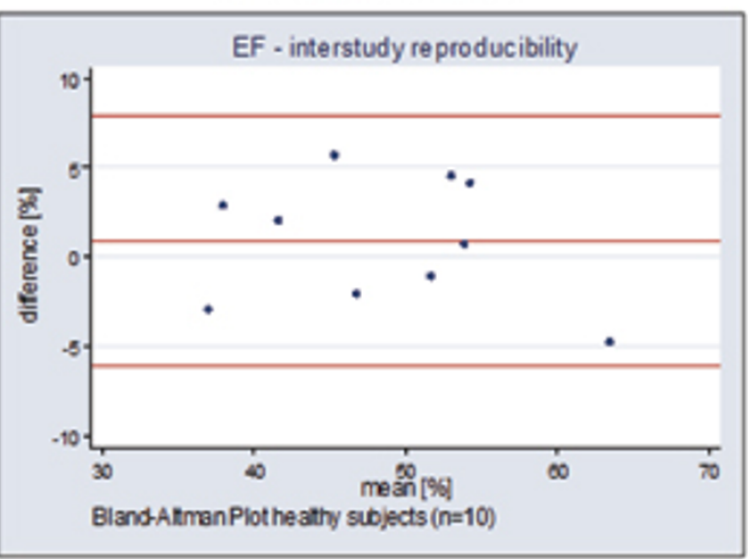

A

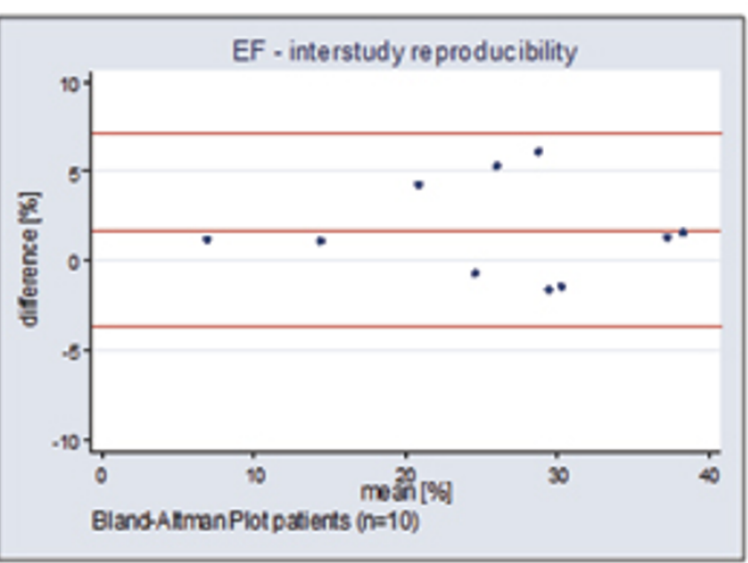

Area-lengthmethod
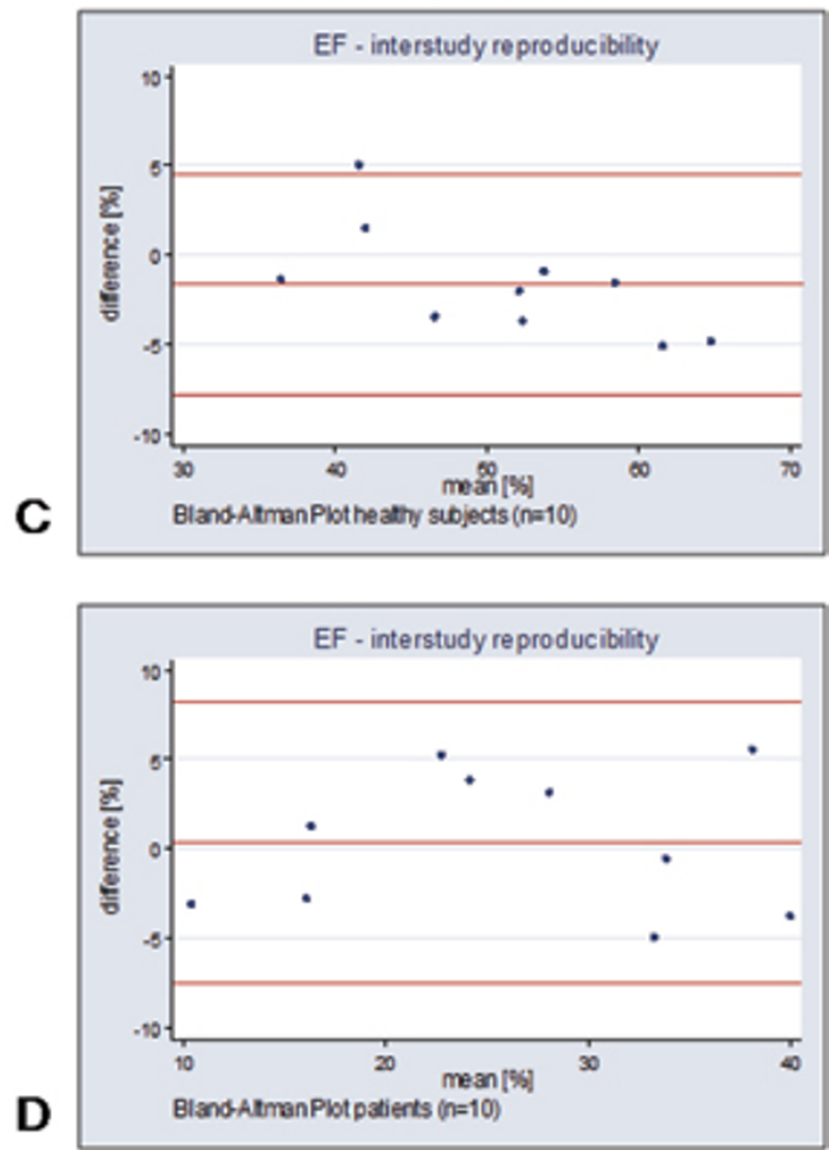

Figure I

The standard short axis method provides reproducible measurements for right atrial volumes and EF. Reproducibility for ALM is moderately lower, but still reasonable. For most accurate reproducibility assessment the standard short axis method should be preferred.

\section{Conclusion}

The standard short axis method provides reproducible measurements for right atrial volumes and EF. Reproducibility for ALM is moderately lower, but still reasonable. For most accurate reproducibility assessment the standard short axis method should be preferred. 
Table I: Absolute values of difference between Scan I and 2

\begin{tabular}{|c|c|c|c|c|c|}
\hline \multirow[t]{2}{*}{ Healthy subjects } & \multicolumn{2}{|c|}{ area length } & \multicolumn{2}{|l|}{ SA } & \multirow[t]{2}{*}{ P-value* } \\
\hline & mean & sd & mean & sd & \\
\hline maximum volume $[\mathrm{ml}]$ & 9.6 & 4.1 & 5.6 & 1.8 & 0.023 \\
\hline minimum volume $[\mathrm{ml}]$ & 6.0 & 3.1 & 3.5 & 1.2 & 0.082 \\
\hline \multirow[t]{2}{*}{ patients } & \multicolumn{2}{|c|}{ Patients } & SA & & p-value* \\
\hline & mean & sd & mean & sd & \\
\hline maximum volume $[\mathrm{ml}]$ & 14.1 & 4.6 & 6.1 & 1.0 & 0.000 \\
\hline minimum volume $[\mathrm{ml}]$ & 7.9 & 3.5 & 3.9 & 1.2 & 0.013 \\
\hline $\mathrm{EF}[\%]$ & 2.7 & 1.6 & 0.9 & 0.4 & 0.010 \\
\hline maximum volume $[\mathrm{ml}]$ & 14.1 & 4.6 & 6.1 & 1.0 & 0.000 \\
\hline
\end{tabular}

*p-value Mann-Whitney two-sample statistic.

Publish with Biomed Central and every scientist can read your work free of charge

"BioMed Central will be the most significant development for disseminating the results of biomedical research in our lifetime. " Sir Paul Nurse, Cancer Research UK

Your research papers will be:

- available free of charge to the entire biomedical community

- peer reviewed and published immediately upon acceptance

- cited in PubMed and archived on PubMed Central

- yours - you keep the copyright

Submit your manuscript here:

http://www.biomedcentral.com/info/publishing_adv.asp 